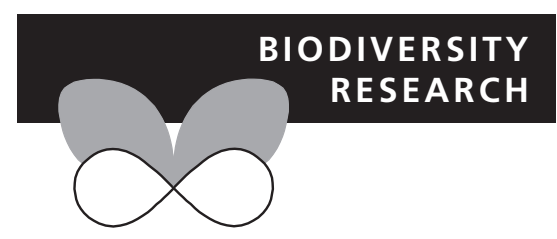

\title{
Additive effects of climate change on connectivity between marine protected areas and larval supply to fished areas
}

\author{
Marco Andrello ${ }^{1,2,3 \star}$, David Mouillot ${ }^{4,5}$, Samuel Somot ${ }^{6}$, \\ Wilfried Thuiller ${ }^{2,3}$ and Stéphanie Manel ${ }^{1,7}$
}

${ }^{1}$ IRD, Aix Marseille Université, LPED UMR 151, Marseille, France, ${ }^{2}$ LECA, Univ. Grenoble Alpes, F-38000 Grenoble, France, ${ }^{3}$ CNRS, LECA, F-38000 Grenoble, France, ${ }^{4} U M R 5119$ - Écologie des Systèmes marins côtiers, Université Montpellier 2, cc 093, Place E. Bataillon, 34095 Montpellier Cedex 5, France, ${ }^{5}$ ARC Centre of Excellence for Coral Reef Studies, James Cook University, Townsville, Qld 4811, Australia, ' ${ }^{6}$ MétéoFrance, Centre National de Recherches Météorologiques CNRM-GAME, 42 Avenue Gaspard Coriolis, 31057 Toulouse Cedex, France, ${ }^{7}$ Centre de coopération internationale en recherche agronomique pour le développement, UMR AMAP, Montpellier, France

${ }^{*}$ Correspondence: Marco Andrello, IRD, Aix Marseille Université, LPED UMR 151, Marseille, France. E-mail: marco.andrello@gmail.com

\begin{abstract}
Aim To study the combined effects of climate change on connectivity between marine protected areas (MPAs) and larval supply to the continental shelf.

Location The Mediterranean Sea, where sea surface temperatures are expected to strongly increase by the end of the 21 st century, represents an archetypal situation with a dense MPA network but resource overexploitation outside.

Methods Using an individual-based mechanistic model of larval transport, forced with an emission-driven regional climate change scenario for the Mediterranean Sea, we explored the combined effects of changes in hydrodynamics, adult reproductive timing and larval dispersal on the connectivity among MPAs and their ability to seed fished areas with larvae.
\end{abstract}

Results We show that, over the period 1970-2099, larval dispersal distances would decrease by $10 \%$, the continental shelf area seeded with larvae would decrease by $3 \%$ and the larval retention fraction would increase by $5 \%$, resulting in higher concentration of larvae in smaller areas of the continental shelf. However, connectance within the MPA network would increase by $5 \%$ as more northern MPAs would become suitable for reproduction with increasing temperatures. We also show that the effects of changes in adult reproductive timing and larval dispersal on connectivity patterns are additive.

Main conclusions Climate change will influence connectivity and the effectiveness of MPA networks, and should receive more attention in future conservation planning and large-scale population dynamics.

\section{Keywords}

Biophysical model, conservation planning, Epinephelus marginatus, larval dispersal, larval growth rate, reproductive timing.

\section{INTRODUCTION}

Habitat destruction and fragmentation through human activities threaten species survival mainly because of the isolation of local populations (Vitousek et al., 1997; Sala et al., 2000; Foley et al., 2005). Local isolated populations are often of small size and are at risk of extinction through demographic and genetic stochasticity (Gilpin \& Soulé, 1986; Gaggiotti \& Hanski, 2004; Frankham, 2005). The isolation of local populations also limits the rescue of already imperilled populations [i.e. rescue effect; (Schiffers et al., 2013)] and the possibilities of (re)colonization for empty habitat patches (Hanski \& Gaggiotti, 2004).
Reducing the risk of species extinction requires both limiting habitat loss and avoiding population isolation. Protected areas (PAs) appear as effective tools to protect species from extinction through habitat conservation (Halpern, 2003; Rodrigues et al., 2004). However, to avoid population isolation, PAs must represent a connected ecological network at the landscape or regional scale (Noss \& Daly, 2006). Only connected networks allow individual movements among PAs through the matrix of unprotected habitats (Lindenmayer et al., 2008). It is now well recognized that landscape connectivity - dispersal in heterogeneous landscape (Taylor et al., 1993; Kool et al., 2012; Baguette et al., 2013) - is an essential feature for the performance of PA networks. 
Landscape connectivity, through the movements of individuals and genes in the landscape, influences population viability, metapopulation persistence and resilience to disturbance (Crooks \& Sanjayan, 2006). In the case of exploited species, landscape connectivity also determines the potential benefits of PAs for areas open to harvest. This aspect is widely acknowledged for marine species, for which marineprotected areas (MPAs) can act as a source of adult spillover or larval export for nearby fished areas. For terrestrial species, emigration from PAs allows for recolonization of empty patches and increases yield for game species subject to hunting (Ahlering et al., 2012; Tolon et al., 2012; Di Minin et al., 2013).

The functioning and effectiveness of PA networks will further depend on the effects of global climate change both on species distribution (Edwards \& Richardson, 2004; Parmesan, 2006; Bellard et al., 2012) and connectivity. Accounting for climate change effects on connectivity when planning future networks has been neglected so far while it is a crucial aspect of systematic conservation planning (Magris et al., 2014). However, connectivity among PAs will be affected by direct and indirect effects on landscape structure and individual dispersal abilities, acting on the emigration, transfer and immigration phase of dispersal (Travis et al., 2013). For example, the dispersal patterns of wind-dispersed plants will change as a result of changes in wind patterns (Bullock et al., 2012); the initiation of migration in moths is positively dependent on temperature and will shift temporally following temperature increase (Battisti et al., 2006). Moreover, these structural and functional changes can interact in a potentially synergistic, additive or antagonistic way (Doak \& Morris, 2010; Lischka \& Riebesell, 2012; Brochier et al., 2013). Scenarios are thus urgently needed to disentangle the various effects by considering all processes, mechanisms, predictions and uncertainties.

In this work, we will illustrate the effects of climate change on connectivity for the network of MPAs in the Mediterranean Sea. MPAs have been established around the globe to counteract the ever increasing over-exploitation of resources (Halpern, 2003). MPAs are indisputably valuable management tools as they promote habitat and species conservation, but also provide additional income from fishing through individual spillover and larval dispersal beyond MPA boundaries (Gaines et al., 2010). The effectiveness of MPAs in protecting species and providing fisheries benefits is critically dependent on connectivity (Almany et al., 2009). For most coastal marine species, especially sessile and benthic species, connectivity is achieved thanks to larval dispersal (Galindo et al., 2006; Cowen \& Sponaugle, 2009; Kool et al., 2010) and must be high enough to ensure ecological and evolutionary links among MPAs and sufficient larval export towards exploited areas (Hastings \& Botsford, 2003; Botsford et al., 2009; Gaines et al., 2010). Up to now, however, few studies have accounted for the impact of climate change on future connectivity patterns (Ayata et al., 2010; Lett et al., 2010), and none has explicitly addressed whether
MPA networks will continue to ensure population persistence.

The mechanisms controlling larval dispersal and their response to the changing environmental conditions will dictate how connectivity will change in the future (Munday et al., 2009a; Lett et al., 2010; Brochier et al., 2013). Date of spawning, number of spawned larvae, larval mortality, behaviour, growth but also modifications of the seascape through changes in sea currents and habitat availability will be influenced by such environmental modifications (Munday et al., 2009a). These interacting processes, all sensitive to climate change, are thus likely to influence the geographic extent of larval transport and the final pattern of connectivity, potentially imperilling the ability of MPA networks to sustain exploited populations. Indeed, spawning time is expected to shift with climate warming as a result of increased temperatures and the dependence of spawning behaviour on environmental clues such as temperature (Lett et al., 2010). Larval growth rates can then increase thanks to faster metabolic activity (O'Connor et al., 2007; Munday et al., 2009a), allowing larvae to attain metamorphosis quicker and thus reducing the duration of larval transport and potentially inducing a lower connectivity. Finally, climate change also modifies hydrodynamics, sea-atmosphere exchanges and ultimately the patterns of sea current velocities (direction and speed) (Somot et al., 2006; Durrieu de Madron et al., 2011; Dubois et al., 2012; Brochier et al., 2013), which could alter the dispersal routes of larvae. Here, we investigate how these three processes, namely change in reproductive timing, change in larval growth rates and change in current velocities, are likely to affect, alone or in combination, connectivity patterns among MPAs and larval supply to fished areas under climate change. Moreover, we test whether these aspects would have additive, synergistic or antagonistic effects, that is, whether combined effects are simply predictable from single effects (additive) or whether the effects amplify (synergy) or inhibit (antagonism) each other in a non-additive manner. We use the Mediterranean Sea as an archetypal situation where (1) there is a dense MPA network (Micheli et al., 2013) (Fig. 1a), (2) sea surface temperatures are expected to strongly increase by the end of the 21 st century $\left[+2.8{ }^{\circ} \mathrm{C}\right.$ for an IPCC-A2 scenario for example in the study of Somot et al. (2006)] (Fig. 1b and c), and (3) where many fish species are overexploited with population persistence depending on conservation effort (Coll et al., 2012).

\section{METHODS}

\section{Spatial distribution of MPAs}

The Mediterranean Sea contains approximately a 100 coastal MPAs of various sizes (Abdulla et al., 2009). MPAs were digitized on the basis of MedPan data (http://www.medpan.org/) as well as from maps, polygons and GPS coordinates provided by managers (Mouillot et al., 2011; Andrello et al., 2013) (Fig. 1a). 
(a)

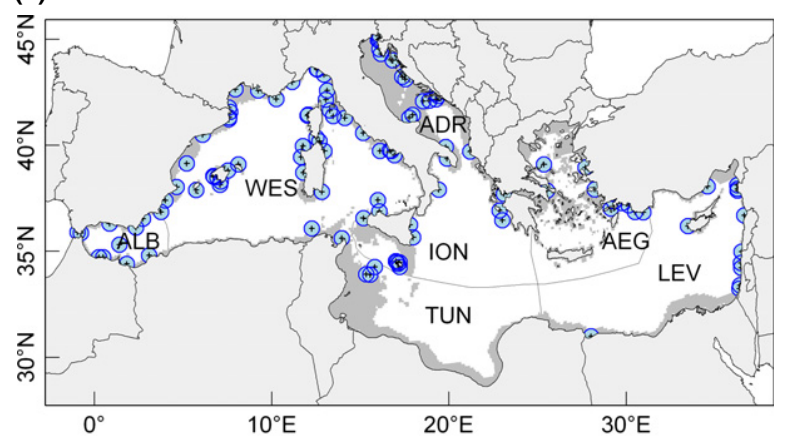

(b)

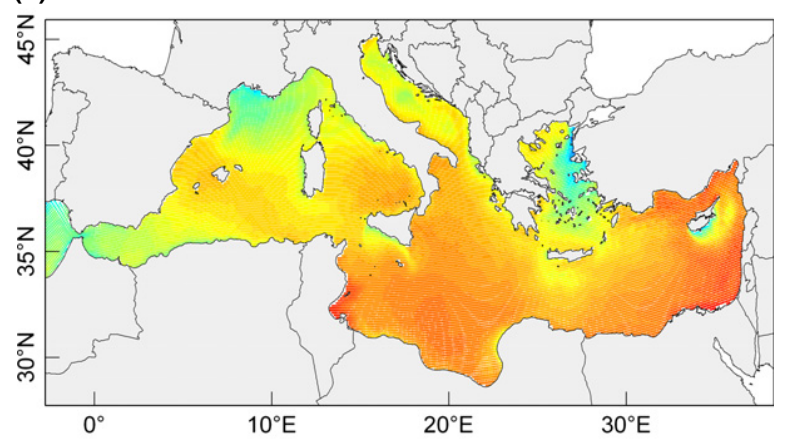

(c)

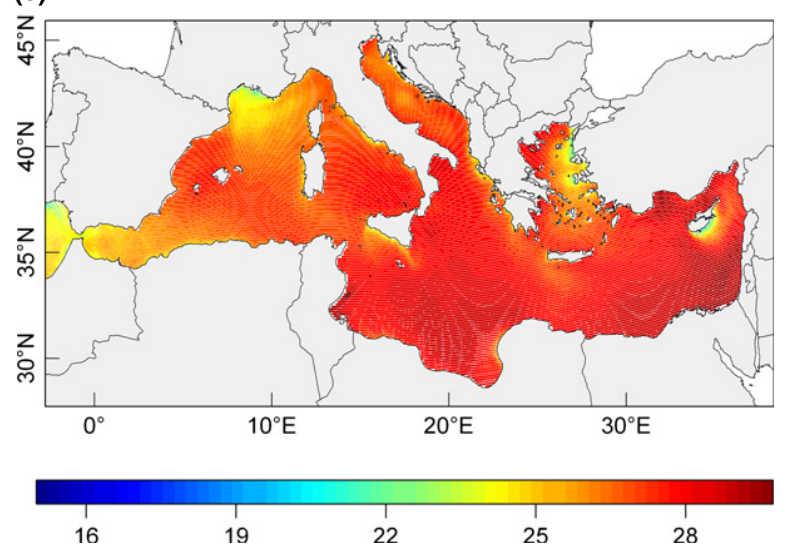

Figure 1 The locations of the 99 MPAs and the Mediterranean ecoregions (Spalding et al., 2007) (a) and sea surface temperatures in 1970-1999 (b) and 2070-2099 (c). ALB, Alboran Sea; WEST, Western Mediterranean; TUN, Tunisian Plateau and Gulf of Sidra; ION, Ionian Sea; ADR, Adriatic Sea; AEG, Aegean Sea; LEV, Levantine Sea. The size of blue circles in (a) does not reflect MPA size. Temperatures are averages over daily temperatures in August for the two periods.

\section{Hydrodynamic model and larval dispersal simulation}

Three-dimensional sea current velocities were obtained from a transient scenario simulation (1970-2099) following the IPCC-A2 hypothesis and carried out with the Mediterranean regional ocean circulation model NEMOMED8 (Beuvier et al., 2010). The ocean model forcings and the hydrodynamic modelling methodology follow Somot et al. (2006).

Daily outputs of zonal and meridional velocities from NEMOMED8 were used to simulate larval dispersion using the software IсHтHYo 3.2 (Lett et al., 2008). For a single year, we released 10,000 larvae per MPA, providing a lower limit of 0.0001 for connection probability. Larval releases in the centroid of each MPA were spread over summer months (1 July-15 September), according to the spawning rules defined below.

Functional relationships and parameters for larval release, growth, settlement and adult spawning were set following field observations and laboratory study carried out on the dusky grouper (Epinephelus marginatus Lowe, 1834), which is sedentary to coastal reefs and territorial in its adult phase (Lembo et al., 1999; Pastor et al., 2009; Afonso et al., 2011). Due to its slow growth and late maturation (Renones et al., 2007, 2010), E. marginatus should be considered as a 'conservation-dependent' species, a species for which the role of MPAs is critical for maintaining a viable population (Afonso et al., 2011; Andrello et al., 2013). Observations of spawning in the field showed that a threshold temperature of $23{ }^{\circ} \mathrm{C}$ must be attained for spawning behaviour to take place (Hereu et al., 2006). According to larval rearing studies, larvae reach $\sim 20 \mathrm{~mm}$ body length in $\sim 30$ days at $23{ }^{\circ} \mathrm{C}$ constant temperature (Cunha et al., 2009), suggesting a mean daily length increment $\sim 0.66 \mathrm{~mm}^{\text {day }}{ }^{-1}$. Larvae become competent to settle between 15 and $20 \mathrm{~mm}$ body length (Cunha et al., 2009), so we set settlement length $L_{S}=15 \mathrm{~mm}$. Larvae were subject to passive transport only without active swimming behaviour. We then tested the sensitivity of model results to settlement length and to larval behaviour (see 'sensitivity analyses' below). Further details on the hydrodynamic model and larval dispersal simulation are given in Appendix S1 in Supporting Information.

\section{Connectivity variables}

Four variables produced by our simulation of larval dispersal were used to measure connectivity among MPAs and larval export to fished areas (Andrello et al., 2013):

1. Larval dispersal distance: measured as the great-circle distance between the positions of larvae at the end and at the beginning of larval transport. The reported value is the median value over all larvae and MPAs.

2. Connectance: the percentage of connections with non-zero probability out of the total number of connections between MPAs. Connectance is a measure of connectivity for the system of MPAs as a whole and is indicative of the ability of the system to act as a true network.

3. Seeded area: area of the continental shelf seeded from MPAs, calculated as the percentage of grid cells containing at least 1 larva out of the total number of grid cells. This metric and the following one (retention) are indicative of the ability of MPAs to provide benefits to exploited areas. Specifically, the extent of seeded area measures the spatial balance of the larval export that may benefit fisheries.

4. Retention: larval retention on the continental shelf - the percentage of released larvae over the continental shelf at the end of larval transport out of the total number of released 
larvae - indicates the magnitude of larval export benefits by taking into account the loss of larvae to unfavourable habitats.

\section{Scenario analyses}

Temperature ( $\mathrm{T}$ ) affects the timing of adult spawning and the rate of larval growth. We explored four scenarios including or not these two temperature-dependent processes (baseline, growth, spawning, combined). In the first scenario (baseline), larvae were released every day independently of temperature and their growth rate was independent of temperature $\left(0.66 \mathrm{~mm} \mathrm{day}^{-1}\right)$. This scenario gives the expected change in connectivity due to changes in sea current velocities only. In the second scenario (growth), larval releases were independent of temperature, but larval growth was temperaturedependent. For simplicity, we used a linear relationship between larval growth rate and $\mathrm{T}$, even if the real relationship might be more complex (e.g. Gaussian). Larval growth rate was $0.027 \mathrm{~T}$; this value was chosen to recover the daily growth rate $\left(0.66 \mathrm{~mm}\right.$ day $\left.^{-1}\right)$ when $\mathrm{T}=23{ }^{\circ} \mathrm{C}$. This scenario reproduces the effects of changes in current velocities and larval growth on connectivity. In the third scenario (spawning), larval releases were temperature-dependent, and larval growth was temperature-independent. Larvae were released when $\mathrm{T}$ in the release point was above $23{ }^{\circ} \mathrm{C}$. This resulted in a different number of larval releases per MPA, but the total number of released larvae was kept constant (10,000 per year and MPA). This scenario gives the expected change in connectivity due to changes in current velocities and spawning time. In the fourth scenario (combined), both larval releases and larval growth were temperature-dependent. The fourth scenario reproduces the combined effects of changes in current velocities, larval growth and spawning time on connectivity. Each scenario took approximately 310 days of total computing time, subdivided into parallel runs of 30 minutes each on the CIMENT computing grid infrastructure (https://ciment.ujfgrenoble.fr).

For each scenario, we estimated the relationship between response variables (dispersal distance, connectance, seeded area and retention fraction) and time, and we tested for the additivity of the growth and spawning effects using a linear model

$$
y=\beta_{0}+\beta_{1} t+\beta_{2} s+\beta_{3} g+\beta_{4} s g+\beta_{5} t s+\beta_{6} t g+\beta_{7} t s g+\varepsilon
$$

Here, $y$ is the response variable (one of dispersal distance, connectance, seeded area and retention), $t$ is the year and $\varepsilon$ is the error term. $s$ and $g$ are dummy variables defining spawning and growth: $s=0$ for temperature-independent spawning (base and growth scenarios) and $s=1$ for temperature-dependent spawning (spawning and combined scenarios). Similarly, $g=0$ for temperature-independent growth (base and spawning scenarios) and $g=1$ for temperature-dependent growth (growth and combined scenario). The year $t$ was transformed by subtracting 1970 so that the intercept terms $\left(\beta_{0}, \beta_{2}, \beta_{3}\right.$ and $\left.\beta_{4}\right)$ are the predicted response variables at the beginning of the series (year 1970). The intercept coefficient $\left(\beta_{0}\right)$ is then the predicted value of the response variables in 1970, while the year coefficient $\left(\beta_{1}\right)$ is the annual increase in the response variables when larval growth and adult spawning are independent on temperature. The growth $\left(\beta_{2}\right)$ and spawning $\left(\beta_{3}\right)$ coefficients are the effects of larval growth and adult spawning, respectively, on the explanatory variables in 1970, and the interaction between them indicate whether this effect is additive $\left(\beta_{4}=0\right)$, compensatory $\left(\beta_{4}<0\right)$ or synergistic $\left(\beta_{4}>0\right)$. The interaction between growth and year $\left(\beta_{5}\right)$ and between spawning and year $\left(\beta_{6}\right)$ are the effects of larval growth and spawning, respectively, on the annual increase of response variables. The interaction between year, growth and spawning indicates whether these effects are additive $\left(\beta_{7}=0\right)$, compensatory $\left(\beta_{7}<0\right)$ or synergistic $\left(\beta_{7}>0\right)$. We used a stepwise procedure for selecting the optimal model both backward from the full model and forward from the null model on the basis of the Akaike Information Criterion, in $\mathrm{R}$ (R Core Team, 2012). The backward and forward procedure always converged to the same model. Ninety-five per cent confidence intervals for regression lines were estimated through the $\mathrm{R}$ function stat_smooth in package ggplot2 (Wickham, 2009). See Appendix S1 for further details on statistical analyses and sensitivity analyses.

\section{RESULTS}

For dispersal distance, connectance and seeded area, the best model includes year, spawning, and growth as explanatory variables, and the interaction between year and growth and between year and spawning (Table 1). For retention, the best model includes year and growth and the interaction between them. The interaction between growth and spawning $\left(\beta_{4}\right)$ is always dropped, indicating that the effects of larval growth and adult spawning on connectivity are additive. Similarly, the interaction between growth, spawning and year $\left(\beta_{7}\right)$ is always dropped, indicating that the effects of larval growth and adult spawning on the annual increase in connectivity are additive: the slope of red lines in Fig. 2 (combined effects of larval growth and adult spawning) is the sum of the slopes of the grey, blue (adult spawning) and green (larval growth) lines. The residuals of all models are normally distributed and have homogenous variances, confirming the appropriateness of the linear relationship for modelling the four response variables.

Dispersal distances are expected to decrease by $4 \%$ as a consequence of hydrodynamic changes only. The adult spawning coefficient $\left(\beta_{5}\right)$ is not significant, indicating that changes in adult spawning timing would not affect this decrease in dispersal distances. The change in larval growth rate would further magnify the decrease in dispersal distances, which would be reduced by $10 \%$ by the end of this 
Table 1 Fitted linear models for the four connectivity variables

\begin{tabular}{|c|c|c|c|c|c|c|c|c|}
\hline & $\begin{array}{l}\text { Intercept } \\
\beta_{0}\end{array}$ & $\begin{array}{l}\text { Year } \\
\beta_{1}\end{array}$ & $\begin{array}{l}\text { Spawning } \\
\beta_{2}\end{array}$ & $\begin{array}{l}\text { Growth } \\
\beta_{3}\end{array}$ & $\begin{array}{l}\text { Year*Spawning } \\
\beta_{5}\end{array}$ & $\begin{array}{l}\text { Year*Growth } \\
\beta_{6}\end{array}$ & Adj- $R^{2}$ & $p$ \\
\hline Dispersal distance & $78.202 * * *$ & $-0.026^{*}$ & $-2.583^{*}$ & $12.904 * * *$ & 0.025 & $-0.067 * * *$ & 0.3811 & $<2.2 \times 10^{-16}$ \\
\hline Connectance & $0.02839 * * *$ & 0.00000 & $-0.00228 * * *$ & $0.00167^{* * *}$ & $0.00002 * * *$ & $-0.00001^{* * *}$ & 0.24780 & $<2.2 \times 10^{-16}$ \\
\hline Seeded area & $0.73572 * * *$ & $-0.00010^{* *}$ & $-0.00795^{* *}$ & $0.01593^{* * *}$ & $0.00007^{*}$ & $-0.00016^{* * *}$ & 0.1734 & $<2.2 \times 10^{-16}$ \\
\hline Retention & $0.71665 * * *$ & -0.00003 & & $-0.04965^{* * *}$ & & $0.00026^{* * *}$ & 0.75180 & $<2.2 \times 10^{-16}$ \\
\hline
\end{tabular}

*, $0.01<p<0.05 ; * *, 0.001<p<0.01 ; * * *, p<0.001$.
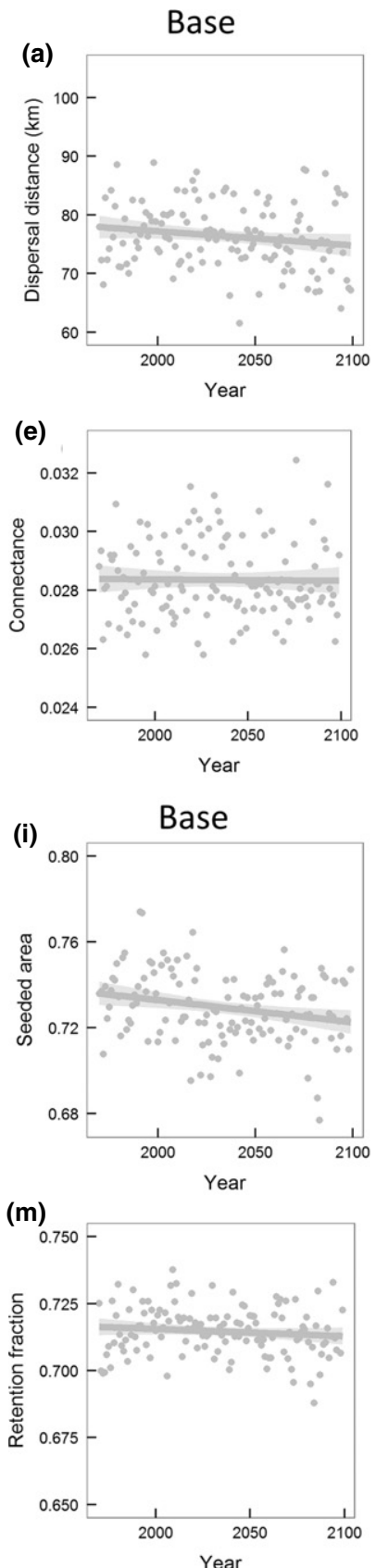

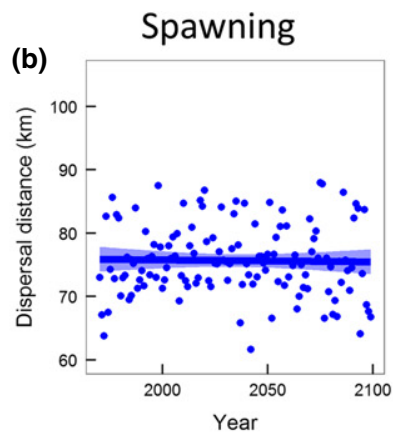

(f)
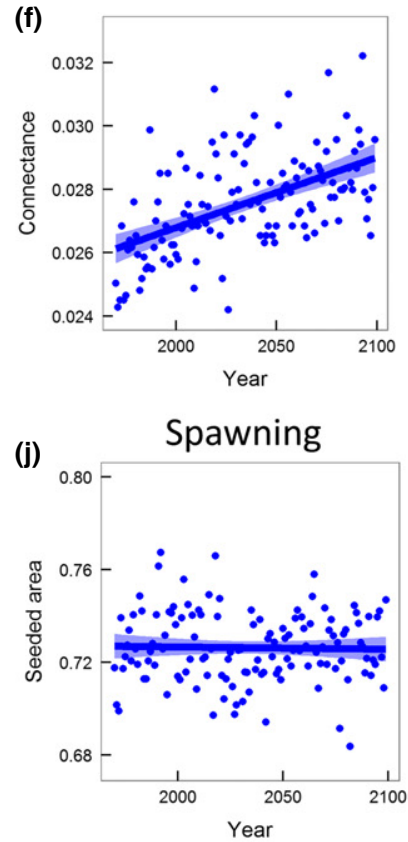

(n)

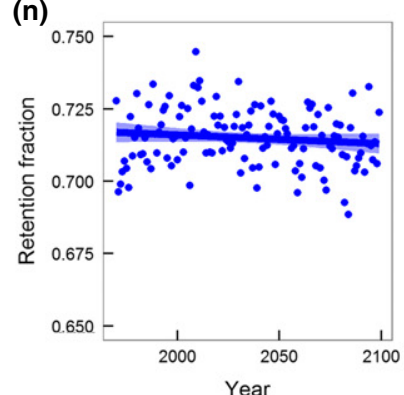

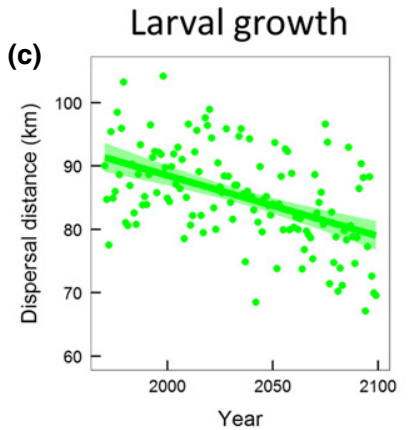
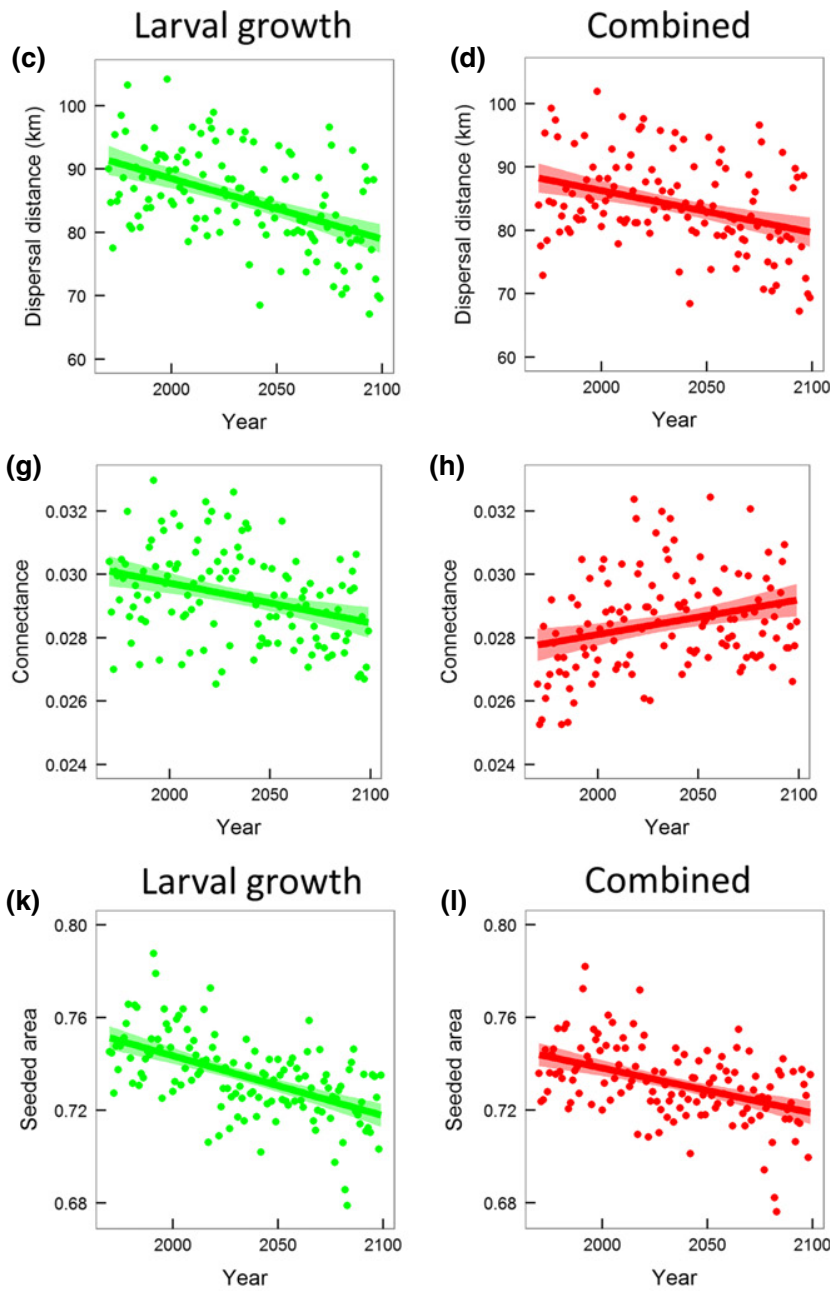

(o)

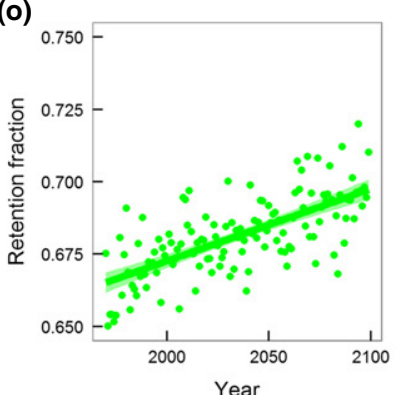

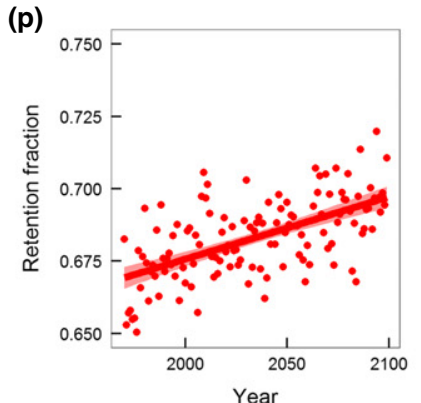

Figure 2 Regression of connectivity variables on time in the four simulation scenarios. (a, b, c, d) Dispersal distance; (e, f, g, h) connectance; $(i, j, k, 1)$ seeded area; and $(m, n, o, p)$ retention. Solid lines are estimated regressions and shaded areas are $95 \%$ confidence intervals. 
century (Fig. 2d). Thus, the effect of climate change on larval growth rates would be more important than those on adult spawning timing and hydrodynamics.

By contrast, the temporal changes in connectance are driven by the effects of temperature on adult spawning timing. While hydrodynamics changes do not affect connectance, changes in adult spawning timing increase connectance by $11 \%$. The effects of temperature on larval growth would mitigate this increase, leading to a net 5\% increase in connectance due to the combined effects of climate change on hydrodynamics, larval growth and adult spawning timing (Fig. 2h). Maps showing connections between MPAs for present and future periods (Fig. 3) confirm that the general pattern of spatial connectivity would remain unchanged, but long-distance connections are expected to be lost.

The area of continental shelf seeded by MPAs would slightly decrease with climate change. In the absence of effects on adult spawning timing and larval growth, changes in hydrodynamics alone would lead to a $2 \%$ reduction in seeded area. The effect of temperature on adult spawning would mitigate this trend and produce $<1 \%$ of decrease in seeded area, while the effects of temperature on larval growth would accentuate it, resulting in a 5\% decrease. The net effect of all processes would be a $3 \%$ decrease in seeded area (Fig. 2l).
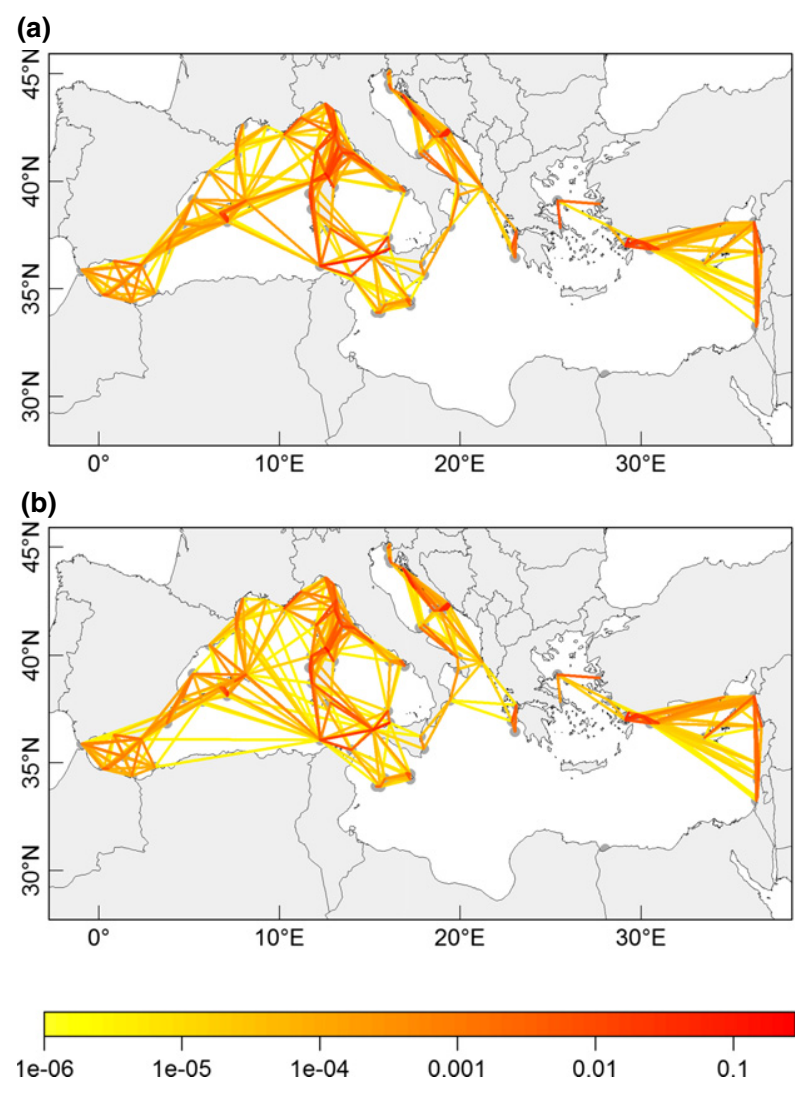

Figure 3 Connections between MPAs for 1970-1999 (a) and 2070-2099 (b). Colours represent the probability of connections.
Hydrodynamic changes would not influence the fraction of larvae retained on the continental shelf (larval retention), as the year coefficient $\left(\beta_{1}\right)$ is not significant. Similarly, changes in adult spawning timing would have no effect on retention, since the spawning variable is dropped from the best model. Conversely, the effects of climate change on larval growth rates would lead to a $5 \%$ increase in larval retention (Fig. 2p).

Larval behaviour has no effect on the annual change in dispersal distance, connectance, seeded area or retention: the interaction between larval behaviour and time $\left(\beta_{3} \neq 0\right)$ is always dropped from the model (see Table S1 and Fig. S1 in Supporting Information). The same is true for the threshold body length for larval settlement (see Table S2 and Fig. S2 in Supporting Information).

\section{DISCUSSION}

Using an individual-based, mechanistic model of larval transport, forced with an emission-driven regional climate change scenario of the Mediterranean Sea, we have explored the combined effects of changes in hydrodynamics, adult reproductive timing and larval growth rates (both temperaturedependent) on connectivity among MPAs and their ability to seed fished areas with larvae. We have shown that larval dispersal distances would decrease by $10 \%$ and connectance of MPAs would increase by $5 \%$ over the period 1970-2099. The extent of continental shelf seeded by MPAs would also decrease by $3 \%$, while larval retention on the continental shelf would increase by $5 \%$, resulting in higher concentration of larvae in smaller areas of the continental shelf. Thus, we observed that climate change would affect all metrics of connectivity (larval dispersal distance, connectance, area of the continental shelf seeded with larvae and larval retention fraction on the continental shelf) through various additive mechanisms (changes in hydrodynamics, adult reproductive timing and larval growth rates).

\section{Impact of climate change on different metrics of connectivity}

The importance of these mechanisms in response to climate change scenarios depend on which metric of connectivity is considered. While larval dispersal distances would decrease, the connectance of the system of MPAs would be strengthened; the extent of the continental shelf seeded by MPAs would decrease, but the concentration of larvae in the seeded areas would increase.

A decrease in larval dispersal distances would decrease gene flow and strengthen population structure, possibly leading to a more modular and fragmented system (Watson et al., 2011). At the opposite, increased connectance among MPAs would ensure higher probability of population persistence (Hastings \& Botsford, 2006a; Artzy-Randrup \& Stone, 2010), higher metapopulation growth rates (Hanski \& Ovaskainen, 2000), higher resilience to disturbances (Blowes \& 
Connolly, 2012). Increased connectance can also increase gene flow and the spread of genetic variants conferring adaptation to novel environmental conditions. This is relevant in the context of adaptation to climate change itself, where warm-tolerant populations from the Southern Mediterranean may contribute adaptive alleles to Northern less tolerant populations (Bodilis et al., 2003). Examination of connectivity patterns among MPAs can inform the design and placement of new PAs to favour spread of adaptive alleles in order to increase resistance to climate change (Mumby et al., 2011).

The two other metrics of connectivity (extent of the continental shelf seeded by MPAs and the concentration of larvae in the seeded areas) are especially important for exploited species and are directly related to the ability of MPAs to provide benefits to exploited areas in the form of adult spillover and larval supply (Gaines et al., 2010). Larval export from MPAs to fished areas can provide recruitment supply and the magnitude of the benefits depends largely on the larval dispersal capacity and the level of exploitation inside and outside MPAs (Kaplan et al., 2009). Larger benefits are possible for well-enforced MPAs that provide effective protection from fishing and higher productivity compared with exploited areas, and for species with short dispersal distances (Pelc et al. 2010). The decrease in seeded area and the increase in larval retention fraction predicted in our simulations would produce higher concentration of larvae on progressively smaller zones of the continental shelf. The increase in larval concentration, combined with the predicted decrease in larval dispersal distances, can supply exploited areas with higher densities of larvae. However, the benefits of higher larvae densities are counterbalanced by a reduction in seeded area. This would lead to higher benefits for fished areas surrounding MPAs but lower benefits for fished areas that are located too far from MPAs, leading to geographical disparities in the benefits of MPAs for fisheries.

\section{Different mechanisms affecting connectivity under climate change}

The four metrics of connectivity will be affected by climate change through different mechanisms (i.e. hydrodynamics, adult reproductive timing and larval growth rates). We found that changes in hydrodynamics have small effects relative to the two other biological mechanisms. While some studies have evidenced how changes in hydrodynamic driving factors such as wind, temperatures and river discharges can affect connectivity (Ayata et al., 2010; Huret et al., 2010; Brochier et al., 2013), our study shows that hydrodynamic changes over the current century would slightly reduce larval dispersal distances, extent of seeded area and larval retention fraction and would have no effect on connectance.

Adult reproductive timing would have an appreciable effect only on connectance. Adult reproductive timing controls the number of reproductive events per MPA and their temporal distribution. Both the number and the temporal distribution of reproductive events can affect connectivity. In our case, the largest effect seems due to the number of reproductive events. Indeed, our model was based on the dusky grouper, a species whose reproduction is limited by low temperatures. As a consequence, reproductive events (and then larval releases) were not possible in MPAs located in too cold places. Therefore, an increased number of MPAs did not contribute larvae in the first years of the 1970-2099 study period (Fig. S3 in Supporting Information). This decreased connectance in the first years and produced the increasing trend in connectance as more and more MPAs became suitable for reproduction. Conversely, for species limited by high temperature, a reduction in the number of MPAs suitable for reproduction with time and therefore a reduction in connectance is expected. In the Mediterranean, climate warming (high temperatures) limits not only the reproductive potential but also the geographic distribution of some species. Among endemic species, 59\% are predicted to restrict their geographic range over the current century and most of them will also experience high fragmentation (Lasram et al., 2010). For such species, the current system of MPAs will likely lose connectance.

The temporal distribution of reproductive events did not have an appreciable effect on connectivity. Seasonal variation in hydrodynamics shapes the distribution of marine organisms and will affect connectivity patterns if the timing of larval releases is shifted earlier (Ayata et al., 2010). Climate change can cause earlier releases of larvae through temperature increase when adult reproductive biology respond positively to temperature (Lett et al., 2010). In addition, such a physiological response would manifest itself immediately following temperature increase, while temperature-driven changes in current speed and direction would be slower due to the much greater inertia of hydrodynamics. It was therefore expected to see changes in connectivity due to temporal shift in adult reproductive timing. However, in our system, the increased suitability of MPAs to adult reproduction seems more important to explain connectance than the shift in reproductive timing from late to early summer. Possibly, the effects of temporal reproductive shifts can become apparent at smaller spatial scales, while they remain masked at the scale of the whole system of MPAs.

The temperature-driven changes in larval growth rates strongly influence the connectivity pattern through time. As a result of faster larval growth rates, we observed a reduction in dispersal distances, connectance and seeded area and an increase in larval retention. The climatic conditions of the Mediterranean basin are expected to change over the current century, with a SST increase in $[0.8 ; 1.8]^{\circ} \mathrm{C}$ for the $2021-$ 2050 period with respect to $1961-1990$ on average over the entire basin [A1B scenario, (Gualdi et al., 2012)] and an expected increase of $2.8{ }^{\circ} \mathrm{C}$ in the current simulation. As expected, higher temperatures lead to faster metabolic rates and therefore a shorter pre-competency phase for larvae, which reach settlement length faster (O'Connor et al., 2007). However, the increase in metabolic activity will increase 
growth rates only if larvae find enough food and is dependent on the availability and abundance of plankton. The distribution of plankton is expected to become more variable with climate change and may thus reduce effective larval growth rates and even lead to increased larval death rates through starvation (Munday et al., 2009a).

Our statistical analyses did not reveal any significant interaction between changes in adult reproductive timing and larval growth rates. An interaction may be possible if earlier reproduction may expose larvae to different water temperatures through change in dispersal routes, and there is no need to expect that the effect on connectivity will be additive. The absence of an interaction does not mean that the effects of different processes on connectivity can be studied separately, because the simple additivity of the effects can change the predictions not only quantitatively but also qualitatively. For example, disregarding the effects of adult reproductive timing on connectance would erroneously lead to predict that connectance will decrease as a result of increased larval growth rates, while including the adult effects lead us to the conclusion of an increase in connectance.

Several other processes can affect connectivity and are themselves affected by environmental conditions and climate change. These processes can alter connectivity during the emigration, dispersal and immigration phase (Travis et al., 2013). Most important for marine fish are larval mortality, larval behaviour, reproductive output, swimming ability and orientation ability (Cowen et al., 2006; Leis, 2007; Munday et al., 2009a; Ayata et al., 2010; Treml et al., 2012). In particular, reproductive output may be subject to temperature control and thus play in the same manner as the effect we observe on reproductive timing, reinforcing connectance due to increased larval releases. Larval mortality rates may be increased by extreme lethal temperatures or by the increased variability of nutrient supply expected under climate change (Munday et al., 2009a). On the other hand, the shorter duration of larval transport and pre-competency period due to faster metabolic rates may reduce the overall planktonic mortality. While the processes affecting connectivity are numerous and likely have important implications, this is the first time, to our knowledge, that two of these processes (namely adult reproduction and larval growth) are modelled jointly to derive the effects of climate change on connectivity.

\section{Model limitations and assumptions}

Predicting the impact of climate change on larval connectivity is a challenging task because of uncertainties intrinsic to model parameter estimation and collected data: (1) a first source of uncertainty is related to multiple emission scenarios depending on future socio-economic and political choices (IPCC et al., 2001); here, we have used only one scenario to force the atmospheric model, but it remains the only available for the Mediterranean. (2) For a given scenario, there are uncertainties concerning Mediterranean Sea forcings, that is, the atmospheric variables, the near-Atlantic ocean characteristics and the river runoff fluxes; these forcings are used to drive the hydrodynamic model. (3) For a given scenario and a given set of forcings, a third source of uncertainty is the choice of regional ocean model itself; in particular, its physical parameterizations and its horizontal and vertical resolutions are key elements of the model design when trying to reproduce coastal circulation in some areas (such as bays and estuaries) (Largier, 2003; Siegel et al., 2003; Werner et al., 2007). (4) We used the best available knowledge on larval biology for the chosen species (Glamuzina et al., 1998; Spedicato \& Boglione, 2000; Cunha et al., 2009) but growth rates and behaviour in the wild (Macpherson \& Raventos, 2006) will likely differ from the results of laboratory studies; moreover, no data are available on important parameters such as salinity, nutrient availability and natural mortality rates. (5). There is also limited knowledge on adult biology, including species distribution and abundance (Zabala et al., 1997; Lembo et al., 1999; Bodilis et al., 2003; Renones et al., 2007, 2010), and spawning behaviour may differ from the observations used in our work, which were collected in a single study site in North-Western Mediterranean (Hereu et al., 2006). The effect of these uncertainties is discussed in Appendix S2 in Supporting Information.

\section{Implications for conservation and management}

Connectivity is an important criterion for the design and implementation of new PAs (Crooks \& Sanjayan, 2006; Moilanen et al., 2009). In addition to enhancing species persistence and biodiversity representation, in the case of exploited species, connectivity from PAs to unprotected areas can offer benefit for harvesting and economic human activities (Gaines et al., 2010; Tolon et al., 2012). According to the Strategic Plan for Biodiversity adopted by the Convention on Biological Diversity (COP10; www.cbd.int/cop10), protected areas are targeted to cover $10 \%$ of the marine surface and $17 \%$ of terrestrial habitats by 2020 and must form well-connected networks.

In the Mediterranean Sea, this means increasing the geographic extent of MPAs by one order of magnitude, from the actual 1\% (excluding the Pelagos Sanctuary; www.medpan.org/med_mpa_analysis) to the targeted $10 \%$. It is therefore important that new MPAs be created following a systematic strategy for conservation at the scale of the entire Mediterranean basin (Giakoumi et al., 2012; Micheli et al., 2013). The criteria for choosing sites for protection should be based on maximizing the representation of biodiversity (Coll et al., 2010), including phylogenetic and functional diversity (Mouillot et al., 2011) and minimizing the anthropogenic pressures that jeopardize biodiversity (Coll et al., 2012). In addition to representing adequately and comprehensively the spatial distribution of present biodiversity, conservation planning should also aim at protecting the processes that will maintain diversity in the future (Pressey et al., 2007; Almany et al., 2009). Connectivity is one of 
these processes as it is essential to ensure population stability and persistence (Armsworth, 2002; Hastings \& Botsford, 2006b) and justifies the need for further research aimed at better characterizing current patterns of connectivity and predicting their future evolution (Mumby et al., 2011; Lemes \& Loyola, 2013).

To reach a realistic integration of connectivity on conservation planning within a climate change context, we need to consider multiple effects combining several species traits potentially modified under temperature increase and to determine whether such effects are additive, compensating or synergistic on connectivity patterns.

\section{ACKNOWLEDGEMENTS}

We thank Fanny Adloff, Camille Albouy, Damien Georges, Julien Renaud and Florence Sevault for help during the preparation of this work as well as four anonymous reviewers and the associate editor Michael Bode for helpful comments on a previous version of this article. This work was part of the Fishconnect project, funded by the 'Fondation pour la recherche sur la biodiversité' and the Total Foundation. D.M. and S.M. were funded by the Institut Universitaire de France. W.T. received support from the European Research Council under the European Community's Seven Framework Programme FP7/2007-2013 Grant Agreement no. 281422 (TEEMBIO). The simulations were performed using the CIMENT infrastructure (https://ciment.ujf-grenoble.fr), which is supported by the Rhône-Alpes region (GRANT CPER07_13 CIRA: http://www.ci-ra.org) and France-Grille (http://www.france-grilles.fr).

\section{REFERENCES}

Abdulla, A., Gomei, M., Hyrenbach, D. et al. (2009) Challenges facing a network of representative marine protected areas in the Mediterranean: prioritizing the protection of underrepresented habitats. ICES Journal of Marine Science, 66, 22-28.

Afonso, P., Fontes, J. \& Santos, R.S. (2011) Small marine reserves can offer long term protection to an endangered fish. Biological Conservation, 144, 2739-2744.

Ahlering, M.A., Eggert, L.S., Western, D. et al. (2012) Identifying source populations and genetic structure for savannah elephants in human-dominated landscapes and protected areas in the Kenya-Tanzania Borderlands. PLoS ONE, 7, e52288.

Almany, G.R., Connolly, S.R., Heath, D.D. et al. (2009) Connectivity, biodiversity conservation and the design of marine reserve networks for coral reefs. Coral Reefs, 28, 339-351.

Andrello, M., Mouillot, D., Beuvier, J. et al. (2013) Low connectivity between mediterranean marine protected areas: a biophysical modeling approach for the dusky grouper Epinephelus marginatus. PLoS ONE, 8, e68564.
Armsworth, P.R. (2002) Recruitment limitation, population regulation, and larval connectivity in reef fish metapopulations. Ecology, 83, 1092-1104.

Artzy-Randrup, Y. \& Stone, L. (2010) Connectivity, cycles, and persistence thresholds in metapopulation networks. PLoS Computational Biology, 6, e1000876.

Ayata, S.-D., Lazure, P. \& Thiébaut, É. (2010) How does the connectivity between populations mediate range limits of marine invertebrates? A case study of larval dispersal between the Bay of Biscay and the English Channel (North-East Atlantic). Progress in Oceanography, 87, 18-36.

Baguette, M., Blanchet, S., Legrand, D. et al. (2013) Individual dispersal, landscape connectivity and ecological networks. Biological Reviews, 88, 310-326.

Battisti, A., Stastny, M., Buffo, E. \& Larsson, S. (2006) A rapid altitudinal range expansion in the pine processionary moth produced by the 2003 climatic anomaly. Global Change Biology, 12, 662-671.

Bellard, C., Bertelsmeier, C., Leadley, P. et al. (2012) Impacts of climate change on the future of biodiversity. Ecology Letters, 15, 365-377.

Blowes, S.A. \& Connolly, S.R. (2012) Risk spreading, connectivity, and optimal reserve spacing. Ecological Applications, 22, 311-321.

Beuvier, J., Sevault, F., Herrmann, M., Kontoyiannis, H., Ludwig, W., Rixen, M., Stanev, E., et al. (2010) Modeling the Mediterranean Sea interannual variability during 19612000: Focus on the Eastern Mediterranean Transient. Journal of Geophysical Research: Oceans, 115, C08017.

Bodilis, P., Ganteaume, A. \& Francour, P. (2003) Recruitment of the dusky grouper (Epinephelus marginatus) in the north-western Mediterranean Sea. Cybium, 27, 123-129.

Botsford, L.W., Brumbaugh, D.R., Grimes, C. et al. (2009) Connectivity, sustainability, and yield: bridging the gap between conventional fisheries management and marine protected areas. Reviews in Fish Biology and Fisheries, 19, 69-95.

Brochier, T., Echevin, V., Tam, J. et al. (2013) Climate change scenarios experiments predict a future reduction in small pelagic fish recruitment in the Humboldt Current system. Global Change Biology, 19, 1841-1853.

Bullock, J.M., White, S.M., Prudhomme, C. et al. (2012) Modelling spread of British wind-dispersed plants under future wind speeds in a changing climate. Journal of Ecology, 100, 104-115.

Coll, M., Piroddi, C., Steenbeek, J. et al. (2010) The biodiversity of the mediterranean sea: estimates, patterns, and threats. PLoS ONE, 5, e11842.

Coll, M., Piroddi, C., Albouy, C. et al. (2012) The Mediterranean Sea under siege: spatial overlap between marine biodiversity, cumulative threats and marine reserves. Global Ecology and Biogeography, 21, 465-480.

Cowen, R.K. \& Sponaugle, S. (2009) Larval dispersal and marine population connectivity. Annual Review of Marine Science, 1, 443-466. 
Cowen, R.K., Paris, C.B. \& Srinivasan, A. (2006) Scaling of connectivity in marine populations. Science, 311, 522-527.

Crooks, K.R. \& Sanjayan, M. (2006) Connectivity conservation. Cambridge University Press, Cambridge, UK.

Cunha, M.E., Quental, H., Barradas, A., Pousão-Ferreira, P., Cabrita, E. \& Engrola, S. (2009) Rearing larvae of dusky grouper, Epinephelus marginatus (Lowe, 1834), (Pisces: Serranidae) in a semi-extensive mesocosm. Scientia Marina, 73S1, 201-212.

Di Minin, E., Hunter, L.T.B., Balme, G.A. et al. (2013) Creating larger and better connected protected areas enhances the persistence of big game species in the MaputalandPondoland-Albany Biodiversity Hotspot. PLoS ONE, 8, e71788.

Doak, D.F. \& Morris, W.F. (2010) Demographic compensation and tipping points in climate-induced range shifts. Nature, 467, 959-962.

Dubois, C., Somot, S., Calmanti, S. et al. (2012) Future projections of the surface heat and water budgets of the Mediterranean Sea in an ensemble of coupled atmosphereocean regional climate models. Climate Dynamics, 39, 1859-1884.

Durrieu de Madron, X., Guieu, C., Sempéré, R. et al. (2011) Marine ecosystems' responses to climatic and anthropogenic forcings in the Mediterranean. Progress in Oceanography, 91, 97-166.

Edwards, M. \& Richardson, A.J. (2004) Impact of climate change on marine pelagic phenology and trophic mismatch. Nature, 430, 881-884.

Foley, J.A., DeFries, R., Asner, G.P. et al. (2005) Global consequences of land use. Science, 309, 570-574.

Frankham, R. (2005) Genetics and extinction. Biological Conservation, 126, 131-140.

Gaggiotti, O.E. \& Hanski, I. (2004) Mechanisms of population extinction. Ecology, genetics and evolution of metapopulations (ed. by I. Hanski and O.E. Gaggiotti), pp. 337-366. Elsevier Academic Press, Amsterdam, The Netherlands.

Gaines, S.D., White, C., Carr, M.H. \& Palumbi, S.R. (2010) Designing marine reserve networks for both conservation and fisheries management. Proceedings of the National Academy of Sciences USA, 107, 18286-18293.

Galindo, H.M., Olson, D.B. \& Palumbi, S.R. (2006) Seascape genetics: a coupled oceanographic-genetic model predicts population structure of Caribbean corals. Current Biology, 16, 1622-1626.

Giakoumi, S., Mazor, T., Fraschetti, S. et al. (2012) Advancing marine conservation planning in the Mediterranean Sea. Reviews in Fish Biology and Fisheries, 22, 943-949.

Gilpin, M.E. \& Soulé, M.E. (1986) Minimum viable populations: processes of species extinction. Conservation biology: the science of scarcity and diversity (ed. by M.E. Soulé), pp. 19-34. Sinauer Associates, Sunderland, Massachusetts.

Glamuzina, B., Skaramuca, B., Glavic, N. et al. (1998) Egg and early larval development of laboratory reared dusky grouper, Epinephelus marginatus (Lowe, 1834) (Pisces, Serranidae). Scientia Marina, 62, 373-378.
Gualdi, S., Somot, S., Li, L. et al. (2012) The CIRCE simulations: regional climate change projections with realistic representation of the Mediterranean Sea. Bulletin of the American Meteorological Society, 94, 65-81.

Halpern, B.S. (2003) The impact of marine reserves: do reserves work and does reserve size matter? Ecological Applications, 13, S117-S137.

Hanski, I. \& Gaggiotti, O.E. (2004) Ecology, genetics and evolution of metapopulations. Academic Press, Burlington.

Hanski, I. \& Ovaskainen, O. (2000) The metapopulation capacity of a fragmented landscape. Nature, 404, 755-758.

Hastings, A. \& Botsford, L.W. (2003) Comparing designs of marine reserves for fisheries and for biodiversity. Ecological Applications, 13, 65-70.

Hastings, A. \& Botsford, L.W. (2006a) A simple persistence condition for structured populations. Ecology Letters, 9, 846-852.

Hastings, A. \& Botsford, L.W. (2006b) Persistence of spatial populations depends on returning home. Proceedings of the National Academy of Sciences USA, 103, 6067-6072.

Hereu, B., Diaz, D., Pasqual, J. et al. (2006) Temporal patterns of spawning of the dusky grouper Epinephelus marginatus in relation to environmental factors. Marine Ecology-Progress Series, 325, 187-194.

Huret, M., Petitgas, P. \& Woillez, M. (2010) Dispersal kernels and their drivers captured with a hydrodynamic model and spatial indices: a case study on anchovy (Engraulis encrasicolus) early life stages in the Bay of Biscay. Progress in Oceanography, 87, 6-17.

IPCC (2001) Climate change 2001. The scientific basis. Contribution of working group I to the third assessment report of the IPCC. (ed. by J.T. Houghton, Y. Ding, D.J. Griggs, M. Noguer, V. Der, P.J. Linder, X. Dai, K. Maskell and J. Ca), p. 881. Cambridge University Press, Cambridge.

Kaplan, D.M., Botsford, L.W., O'Farrell, M.R. et al. (2009) Model-based assessment of persistence in proposed marine protected area designs. Ecological Applications, 19, 433-448.

Kool, J.T., Paris, C.B., Andréfouët, S. \& Cowen, R.K. (2010) Complex migration and the development of genetic structure in subdivided populations: an example from Caribbean coral reef ecosystems. Ecography, 33, 597-606.

Kool, J., Moilanen, A. \& Treml, E. (2013) Population connectivity: recent advances and new perspectives. Landscape Ecology, 28, 165-185.

Largier, J. (2003) Considerations in estimating larval dispersal distances from oceanographic data. Ecological Applications, 13, S71-S89.

Lasram, F.B., Guilhaumon, F., Albouy, C., Somot, S., Thuiller, W. \& Mouillot, D. (2010) The Mediterranean Sea as a 'cul-de-sac' for endemic fishes facing climate change. Global Change Biology, 16, 3233-3245.

Leis, J.M. (2007) Behaviour as input for modelling dispersal of fish larvae: behaviour, biogeography, hydrodynamics, ontogeny, physiology and phylogeny meet hydrography. Marine Ecology Progress Series, 347, 185-193. 
Lembo, G., Fleming, I.A., Økland, F., Carbonara, P. \& Spedicato, M.T. (1999) Site fidelity of the dusky grouper Epinephelus marginatus (Lowe, 1834) studied by acoustic telemetry. Marine Life, 9, 37-43.

Lemes, P. \& Loyola, R.D. (2013) Accommodating species climate-forced dispersal and uncertainties in spatial conservation planning. PLoS ONE, 8, e54323.

Lett, C., Verley, P., Mullon, C., Parada, C., Brochier, T., Penven, P. \& Blanke, B. (2008) A Lagrangian tool for modelling ichthyoplankton dynamics. Environmental Modelling \& Software, 23, 1210-1214.

Lett, C., Ayata, S.-D., Huret, M. \& Irisson, J.-O. (2010) Biophysical modelling to investigate the effects of climate change on marine population dispersal and connectivity. Progress in Oceanography, 87, 106-113.

Lindenmayer, D., Hobbs, R.J., Montague-Drake, R. et al. (2008) A checklist for ecological management of landscapes for conservation. Ecology Letters, 11, 78-91.

Lischka, S. \& Riebesell, U. (2012) Synergistic effects of ocean acidification and warming on overwintering pteropods in the Arctic. Global Change Biology, 18, 3517-3528.

Macpherson, E. \& Raventos, N. (2006) Relationship between pelagic larval duration and geographic distribution of Mediterranean littoral fishes. Marine Ecology-Progress Series, 327, 257-265.

Magris, R.A., Pressey, R.L., Weeks, R. \& Ban, N.C. (2014) Integrating connectivity and climate change into marine conservation planning. Biological Conservation, 170, 207221.

Micheli, F., Levin, N., Giakoumi, S. et al. (2013) Setting priorities for regional conservation planning in the Mediterranean Sea. PLoS ONE, 8, e59038.

Moilanen, A., Wilson, K.A. \& Possingham, H.P.E. (2009) Spatial conservation prioritization: quantitative methods and computational tools. Oxford University Press, Oxford.

Mouillot, D., Albouy, C., Guilhaumon, F. et al. (2011) Protected and threatened components of fish biodiversity in the Mediterranean Sea. Current Biology, 21, 1044-1050.

Mumby, P.J., Elliott, I.A., Eakin, C.M. et al. (2011) Reserve design for uncertain responses of coral reefs to climate change. Ecology Letters, 14, 132-140.

Munday, P.L., Leis, J.M., Lough, J.M., Paris, C.B., Kingsford, M.J., Berumen, M.L. \& Lambrechts, J. (2009a) Climate change and coral reef connectivity. Coral Reefs, 28, 379395.

Noss, R.F. \& Daly, K.M. (2006) Incorporating connectivity into broad-scale conservation planning. Connectivity conservation (ed. by K.R. Crooks and M. Sanjayan), pp. 517-619. Cambridge University Press, Cambridge.

O'Connor, M.I., Bruno, J.F., Gaines, S.D. et al. (2007) Temperature control of larval dispersal and the implications for marine ecology, evolution, and conservation. Proceedings of the National Academy of Sciences USA, 104, 1266-1271.

Parmesan, C. (2006) Ecological and evolutionary responses to recent climate change. Annual Review of Ecology, Evolution, and Systematics, 37, 637-669.
Pastor, J., Verdoit-Jarraya, M., Astruch, P., Dalias, N., Nelva Pasqual, J., Saragoni, G. \& Lenfant, P. (2009) Acoustic telemetry survey of the dusky grouper (Epinephelus marginatus) in the Marine Reserve of Cerbère-Banyuls: informations on the territoriality of this emblematic species. Comptes Rendus Biologies, 332, 732-740.

Pelc, R.A., Warner, R.R., Gaines, S.D. \& Paris, C.B. (2010) Detecting larval export from marine reserves. Proceedings of the National Academy of Sciences of the United States of America, 107, 18266-18271.

Pressey, R.L., Cabeza, M., Watts, M.E., Cowling, R.M. \& Wilson, K.A. (2007) Conservation planning in a changing world. Trends in Ecology \& Evolution, 22, 583-592.

R Core Team (2012) R: a language and environment for statistical computing. R Foundation for Statistical Computing, Vienna, Austria. ISBN 3-900051-07-0, URL http://www. R-project.org/.

Renones, O., Pineiro, C., Mas, X. \& Goni, R. (2007) Age and growth of the dusky grouper Epinephelus marginatus (Lowe 1834) in an exploited population of the western Mediterranean Sea. Journal of Fish Biology, 71, 346-362.

Renones, O., Grau, A., Mas, X., Riera, F. \& Saborido-Rey, F. (2010) Reproductive pattern of an exploited dusky grouper Epinephelus marginatus (Lowe 1834) (Pisces: Serranidae) population in the western Mediterranean. Scientia Marina, 74, 523-537.

Rodrigues, A.S.L., Andelman, S.J., Bakarr, M.I. et al. (2004) Effectiveness of the global protected area network in representing species diversity. Nature, 428, 640-643.

Sala, O.E., Chapin, F.S., Armesto, J.J. et al. (2000) Biodiversity - global biodiversity scenarios for the year 2100. Science, 287, 1770-1774.

Schiffers, K., Bourne, E.C., Lavergne, S., Thuiller, W. \& Travis, J.M.J. (2013) Limited evolutionary rescue of locally adapted populations facing climate change. Philosophical Transactions of the Royal Society B: Biological Sciences, 368, 20120083.

Siegel, D.A., Kinlan, B.P., Gaylord, B. \& Gaines, S.D. (2003) Lagrangian descriptions of marine larval dispersion. Marine Ecology-Progress Series, 260, 83-96.

Somot, S., Sevault, F. \& Deque, M. (2006) Transient climate change scenario simulation of the Mediterranean Sea for the twenty-first century using a high-resolution ocean circulation model. Climate Dynamics, 27, 851-879.

Spalding, M.D., Fox, H.E., Allen, G.R. et al. (2007) Marine ecoregions of the world: a bioregionalization of coastal and shelf areas. BioScience, 57, 573-583.

Spedicato, M.T. \& Boglione, C. (2000) Main constraints in the artificial propagation of the dusky grouper Epinephelus marginatus (Lowe, 1834): three years experimental trials on induced spawning and larval rearing. Cahiers Options Méditerranéennes, 47, 227-234.

Taylor, P.D., Fahrig, L., Henein, K. \& Merriam, G. (1993) Connectivity is a vital element of landscape structure. Oikos, 68, 571-573.

Tolon, V., Martin, J., Dray, S., Loison, A., Fischer, C. \& Baubet, E. (2012) Predator-prey spatial game as a tool to 
understand the effects of protected areas on harvester-wildlife interactions. Ecological Applications, 22, 648-657.

Travis, J.M.J., Delgado, M., Bocedi, G. et al. (2013) Dispersal and species' responses to climate change. Oikos, 122, 1532-1540.

Treml, E.A., Roberts, J.J., Chao, Y. et al. (2012) Reproductive output and duration of the pelagic larval stage determine seascape-wide connectivity of marine populations. Integrative and Comparative Biology, 52, 525-537.

Vitousek, P.M., Mooney, H.A., Lubchenco, J. \& Melillo, J.M. (1997) Human domination of Earth's ecosystems. Science, 277, 494-499.

Watson, J.R., Siegel, D.A., Kendall, B.E. et al. (2011) Identifying critical regions in small-world marine metapopulations. Proceedings of the National Academy of Sciences USA, 108, E907-E913.

Werner, F.E., Cowen, R.K. \& Paris, C.B. (2007) Coupled biological and physical models present capabilities and necessary developments for future studies of population connectivity. Oceanography, 20, 54-69.

Wickham, H. (2009) ggplot2: elegant graphics for data analysis. Springer, New York.

Zabala, M., GarciaRubies, A., Louisy, P. \& Sala, E. (1997) Spawning behaviour of the Mediterranean dusky grouper Epinephelus marginatus (Lowe, 1834) (Piscea, Serranidae) in the Medes Islands Marine Reserve (NW Mediterranean, Spain). Scientia Marina, 61, 65-77.

\section{SUPPORTING INFORMATION}

Additional Supporting Information may be found in the online version of this article:

Appendix S1 Supplementary methods.
Appendix S2 Supplementary discussion.

Figure S1 Regression of connectivity variables on time in the 'combined' scenario with diel vertical migration: (a) dispersal distance; (b) connectance; (c) seeded area; and (d) retention. Solid lines are estimated regressions and shaded areas are 95\% confidence intervals.

Figure S2 Regression of connectivity variables on time in the 'combined' scenario with increased larval settlement length:

(a) dispersal distance; (b) connectance; (c) seeded area; and

(d) retention. Solid lines are estimated regressions and shaded areas are 95\% confidence intervals.

Figure S3 Number of MPAs with no reproductive events per year in the 'spawning' and 'combined' scenarios.

Table S1 Fitted linear models for the four connectivity variables for the larval migration sensitivity analysis

Table S2 Fitted linear models for the four connectivity variables for the settlement length sensitivity analysis

\section{BIOSKETCH}

Marco Andrello is a population biologist using modelling and fieldwork to study population dynamics and genetics of different species in a variety of ecosystems. His current research focuses on connectivity among marine protected areas and the implications for biodiversity conservation (https://sites.google.com/site/projetfishconnect/).

Editor: Michael Bode 